OPEN ACCESS

Edited by:

Maik Gollasch,

Charité Universitätsmedizin Berlin,

Germany

Reviewed by:

Bradley S. Fleenor,

Ball State University, United States

Keshari Thakali,

University of Arkansas for Medical

Sciences, United States

*Correspondence:

Alexander Pfeifer

alexander.pfeifer@uni-bonn.de

Specialty section:

This article was submitted to

Vascular Physiology,

a section of the journal

Frontiers in Physiology

Received: 21 November 2017

Accepted: 19 January 2018

Published: 06 February 2018

Citation:

Hildebrand S, Stümer $J$ and Pfeifer $A$

(2018) PVAT and Its Relation to

Brown, Beige, and White Adipose

Tissue in Development and Function.

Front. Physiol. 9:70.

doi: 10.3389/fphys.2018.00070

\section{PVAT and Its Relation to Brown, Beige, and White Adipose Tissue in Development and Function}

\author{
Staffan Hildebrand, Jasmin Stümer and Alexander Pfeifer* \\ Institute of Pharmacology and Toxicology, University Hospital Bonn, University of Bonn, Bonn, Germany
}

Adipose tissue is commonly categorized into three types with distinct functions, phenotypes, and anatomical localizations. White adipose tissue (WAT) is the major energy store; the largest depots of WAT are found in subcutaneous or intravisceral sites. Brown adipose tissue (BAT) is responsible for energy dissipation during cold-exposure (i.e., non-shivering thermogenesis) and is primarily located in the interscapular region. Beige or brite (brown-in-white) adipose tissue can be found interspersed in WAT and can attain a brown-like phenotype. These three types of tissues also have endocrine functions and play major roles in whole body metabolism especially in obesity and its co-morbidities, such as cardiovascular disease. Over the last years, perivascular adipose tissue (PVAT) has emerged as an adipose organ with endocrine and paracrine functions. Pro and anti-inflammatory agents released by PVAT affect vascular health, and are implicated in the inflammatory aspects of atherosclerosis. PVAT shares several of the defining characteristics of brown adipose tissue, including its cellular morphology and expression of thermogenic genes characteristic for brown adipocytes. However, PVATs from different vessels are phenotypically different, and significant developmental differences exist between PVAT and other adipose tissues. Whether PVAT represents classical BAT, beige adipose tissue, or WAT with changing characteristics, is unclear. In this review, we summarize the current knowledge on how PVAT relates to other types of adipose tissue, both in terms of functionality, developmental origins, and its role in obesity-related cardiovascular disease and inflammation.

Keywords: PVAT, perivascular, adipose tissue, BAT, inflammation, cardiovascular disease

\section{INTRODUCTION}

During the last decades, the prevalence of obesity has reached pandemic dimensions, doubling since 1990. In 2015, over 600 million obese adults and over 100 million obese children were reported worldwide (Afshin et al., 2017). Obesity is characterized by a high body mass index $(\mathrm{BMI}) \geq 30$. Overweight and obesity are associated with several severe comorbidities, such as cardiovascular disease, type 2 diabetes mellitus, and certain types of cancer (Chen et al., 2016). Importantly, more than two thirds of the deaths related to overweight and obesity were caused by cardiovascular disease (CVD) (Afshin et al., 2017) showing the importance of vascular disease in metabolic disorders. The defining trait in obesity is the abnormal increase in WAT mass with adipocyte hypertrophy and hyperplasia, brought on by an imbalance between energy intake and energy consumption leading to energy overload. This can result in hypertriglyceridemia, insulin 
resistance, and chronic low-grade inflammation first of the adipose tissue and then throughout the whole body (Czech et al., 1977; Hotamisligil, 2006; Guilherme et al., 2008).

In mammals, there are three types of adipose tissues: white, brown and beige. These tissues have distinct functions and consequently have different morphology, protein expression patterns, and developmental origin (Pfeifer and Hoffmann, 2015). The function of white adipose tissue (WAT) is to store energy in the form of lipids, which can be released to fuel other tissues. On the other hand, brown adipose tissue (BAT) has unique thermogenic properties and is a vital organ for maintaining body temperature in smaller mammals and human infants with a high surface-to-volume ratio. Beige or brite (brown-in-white) fat is predominantly found interspersed in WAT depots, but can acquire a brown-like phenotype upon cold exposure or pharmacological stimulation (Chen et al., 2016). In mice, subcutaneous WAT (SAT) has the highest capacity for "browning" or "beiging" (Chen et al., 2016). Figure 1 shows a simplified schematic of the different (murine) adipose tissues discussed in this review.

Perivascular adipose tissue (PVAT) is the fat surrounding the blood vessels, directly adjacent to the vascular wall, and was considered for long time to serve only structural, vesselsupporting purposes. As fat in general is now well known to be a secretory organ, PVAT is today also recognized to be an endocrine organ, actively releasing bioactive molecules such as pro- and anti-inflammatory cytokines and vasoactive substances (Figure 2; Soltis and Cassis, 1991; Gollasch and Dubrovska, 2004; Gao et al., 2007; Britton and Fox, 2011). Over the last years, several studies have been conducted comparing PVAT to other adipose tissues, such as classical BAT and WAT, which we try to summarize in this review. Obesity is associated with an increased risk for CVD and with remodeling of the adipose tissues, both WAT and BAT (Fantuzzi and Mazzone, 2007; Berbée et al., 2015). Given the proximity of PVAT to the vasculature, we also aim to compare the potential impact of PVAT on CVD and vice-versa.

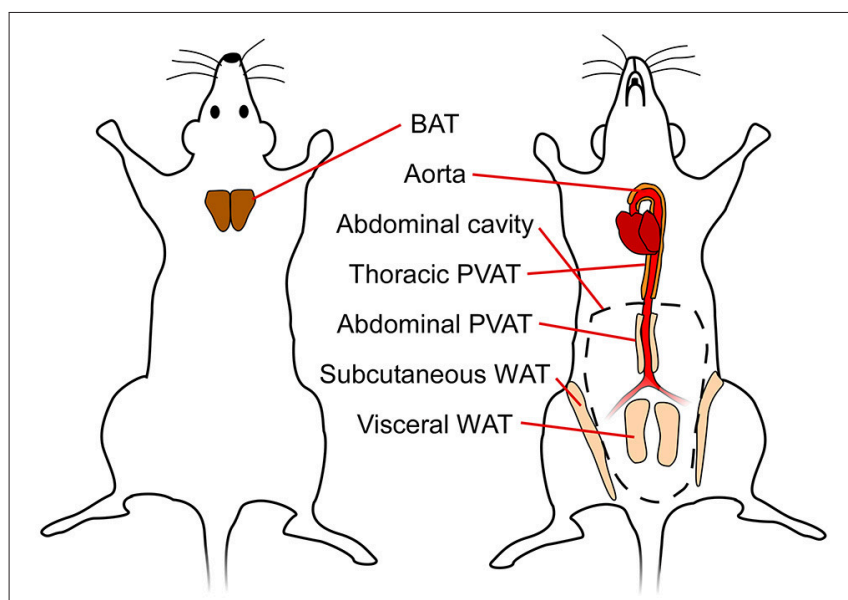

FIGURE 1 | Simplified schematic showing different adipose tissue depots in mice. BAT, brown adipose tissue; WAT, white adipose tissue; PVAT, perivascular adipose tissue.

\section{White Adipose Tissue}

WAT makes up the main mass of adipose tissue in human adults, and represents 10-20 percent of body weight in healthy subjects. WAT is widely distributed through the whole body and is located mainly in subcutaneous regions and surrounding internal organs (visceral adipose tissue, VAT) (Chen et al., 2017). WAT is well known as the major organ to store energy in form of triacylglycerols (TAG), which can be mobilized via lipolysis whenever energy is needed. Lipolysis is initiated by norepinephrine binding to beta-adrenergic receptors. This initiates the production of cyclic adenosine-monophosphate (cAMP), the second messenger which activates hormone sensitive lipase via protein kinase A (PKA), resulting in the release of free fatty acids from stored TAG (Duncan et al., 2007).

Morphologically, white adipocytes contain a single, big lipid droplet occupying most of the cytoplasm, and a peripheral nucleus, which leads to a typical signet ring appearance. WAT also has important endocrine functions secreting hormones and cytokines such as leptin, adiponectin, tumor-necrosis factor $\alpha(\mathrm{TNF} \alpha)$ and interleukin-6 (IL-6) (Chen et al., 2017). Adipogenic differentiation of white adipocytes is regulated by several known transcription factors including CCAAT/enhancerbinding-proteins $\mathrm{C} / \mathrm{EBP} \beta$ and $\mathrm{C} / \mathrm{EBP} \delta$, which in turn regulate expression of peroxisome proliferator-activated factor gamma $(\mathrm{PPAR} \gamma)$ and $\mathrm{C} / \mathrm{EBP} \alpha$. Together, $\mathrm{C} / \mathrm{EBP} \alpha$ and $\mathrm{PPAR} \gamma$ regulate gene transcription and promote differentiation of adipocytes during late WAT adipogenesis (Barak et al., 1999; Rosen et al., 1999; Rosen and MacDougald, 2006; Hudak and Sul, 2013).

\section{Brown Adipose Tissue}

BAT plays a crucial role in generating heat via non-shivering thermogenesis (NST) in newborn humans. NST is achieved through the expression of the mitochondrial protein uncoupling protein-1 (UCP-1), which uncouples the respiratory chain and causes a leak of protons across the mitochondrial membrane (Cannon and Nedergaard, 2004; Pfeifer and Hoffmann, 2015). This process results in the generation of heat instead of adenosine triphosphate (ATP), and is initiated by activation of $\beta-3$ adrenergic receptors $(\beta 3-A R)$ and adenosine $A_{2 A}$ receptors expressed on brown adipocytes (Lowell and Flier, 1997; Gnad et al., 2014). In contrast to white adipocytes, brown adipocytes contain many small lipid droplets leading to a multilocular histological appearance. Furthermore, brown adipocytes contain densely packed mitochondria needed for efficient NST, and is highly vascularised, which taken together causes the characteristic brown color.

Several factors that regulate BAT development have been identified, such as PPAR $\gamma$, peroxisome proliferator-activated receptor gamma coactivator 1 -alpha $(\mathrm{PGC}-1 \alpha)$, orexin, and bone morphogenic factor 7 (BMP7) (Tseng et al., 2008; Hondares et al., 2011; Cohen et al., 2014).

Nowadays, it is well established that not only newborns but also human adults have depots of BAT that are metabolically active during cold exposure. BAT in human adults is mainly found in the supraclavicular, neck, perirenal and mediastinal region (Nedergaard et al., 2007; Cypess et al., 2009; van Marken Lichtenbelt et al., 2009). These findings are is also in agreement 


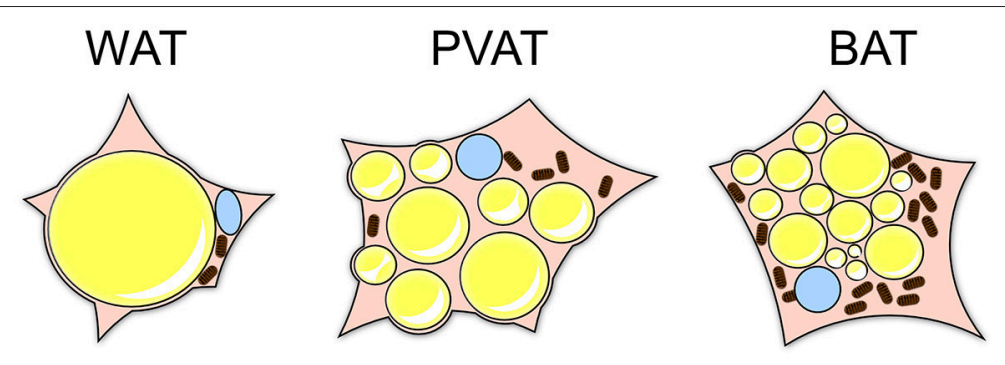

\begin{tabular}{l|lll} 
Lipid content & Very high, single droplet & High, multiple lipid droplets & High, multiple lipid droplets \\
\hline Mitochondrial content & Low & High & Very high \\
\hline UCP1 expression & Very low & Dependent on tissue localization & High \\
\hline Vascularization & $\begin{array}{l}\text { Adequate, compromised } \\
\text { in obesity }\end{array}$ & $\begin{array}{l}\text { In direct contact with adventitia of } \\
\text { blood vessels }\end{array}$ & Highly perfused \\
\hline Function & $\begin{array}{l}\text { Storage of lipids, } \\
\text { endocrine function }\end{array}$ & $\begin{array}{l}\text { Thermogenesis, regulation of vas- } \\
\text { cular tone }\end{array}$ & Thermogenesis \\
\hline Location & $\begin{array}{l}\text { Subcutaneous or } \\
\text { intra-abdominal }\end{array}$ & Around blood vessels & Mainly inter- and subscapular \\
\hline Response to HFD & Hypertrophy, hyperplasia, & Some hypertrophy in thoracic & Some hypertrophy \\
& inflammation (depot & PVAT, Hypertrophy, whitening and & \\
& dependent) & inflammation in abdominal PVAT & \\
\hline
\end{tabular}

FIGURE 2 | Overview of the characteristics of different adipose tissues. BAT, brown adipose tissue; WAT, white adipose tisse; PVAT, perivascular adipose tissue; HFD, high-fat diet; UCP1, uncoupling protein 1.

with earlier post mortem investigations of human adults tissue showing that BAT can be found in deeper regions of the human body, where it might act as a thermogenic protection for internal organs (Heaton, 1972). Interestingly, studies in human adults have demonstrated a reduced BAT activity in obese and overweight subjects. Conversely, BAT mass positively correlates with resting metabolic rate (van Marken Lichtenbelt et al., 2009). During obesity, the adipocytes in interscapular BAT seem to adopt a white-like phenotype, with increased lipid accumulation (Shimizu et al., 2014).

In summary, the presence of active BAT in human adults makes this special type of fat an interesting target for new therapeutic approaches to tackle obesity.

\section{Beige Adipose Tissue}

In response to cold exposure, WAT can adopt a brown-like phenotype in a process called "browning." During browning, UCP-1-expressing brown-like adipocytes, with a high number of mitochondria and multilocular lipid droplets, appear (Lo and Sun, 2013; Pfeifer and Hoffmann, 2015; Chen et al., 2016). These so called beige or brite (brown-in-white) cells also express a number of characteristic markers, such as CD137, Tbx1, and Cited-1 (Harms and Seale, 2013). The capacity for browning varies between the different WAT depots, with SAT being more prone to browning than VAT (Seale et al., 2011). This probably owes mainly to differential expression of PR domain containing 16 (PRDM16) in SAT and VAT. PRDM16 is critical for phenotypic maintenance of classical BAT, and is more highly expressed in SAT than VAT (Seale et al., 2011). Importantly, ablation of PRDM16 in adipocytes disrupts browning of SAT upon cold exposure (Cohen et al., 2014). The interconversion of adipocytes has been reported to be possible in both directions: white adipocytes gain a beige/brite phenotype during cold exposure, and return to a white adipocyte-like appearance after removal of the cold stimulus (Rosenwald et al., 2013).

\section{PVAT AS BROWN ADIPOSE TISSUE}

\section{Similarities and Differences between PVAT vs. BAT, WAT, or Beige Fat}

Several reports (Gálvez-Prieto et al., 2008; Police et al., 2009; Fitzgibbons et al., 2011) indicate that depending on the localization, PVAT can resemble either WAT or BAT. Thoracic periaortic adipose tissue is morphologically similar to BAT, with adipocytes that have a multilocular appearance and round nuclei (Fitzgibbons et al., 2011). A direct comparison of gene expression of thoracic PVAT, interscapular BAT and WAT from mice revealed that only 228 genes (i.e. $0.79 \%$ ) were significantly different between thoracic PVAT and classical BAT (Fitzgibbons et al., 2011). Interestingly, there was no significant difference in the expression levels of the genes known to be typically expressed in classical BAT, such as Cidea, Ucp-1, or PPAR $\gamma$ (Fitzgibbons et al., 2011). Furthermore, proteomic analysis shows striking similarities in protein expression between periaortic adipose tissue and classical BAT, but not WAT (Chang et al., 2012).

In contrast to beige adipose tissue, thoracic PVAT maintains a BAT-like phenotype in the absence of activating stimuli. Furthermore, perivascular adipocytes do not undergo significant 
whitening during high fat diet (HFD) feeding, which is characteristic of BAT (Fitzgibbons et al., 2011). These findings suggest that, from a morphological and functional standpoint, thoracic PVAT more closely resembles classical BAT than beige fat.

Functionally, PVAT also exhibits important similarities with BAT. Chang et al. created a PVAT-deficient mouse by knocking out PPAR $\gamma$ in smooth muscle cells, and were able to show that PVAT significantly contributes to maintaining intravascular temperature during cold exposure. While PVAT activation could not completely rescue the reduction in intravascular temperature caused by resection of BAT, mice lacking both BAT and PVAT had significantly lower intravascular temperature than mice lacking only BAT (Chang et al., 2012).

However, there are also reports characterizing PVAT as WAT or WAT-like (Omar et al., 2014). This discrepancy appears to derive from the anatomical localization of the PVAT. In contrast to thoracic PVAT, the adipose tissue surrounding the abdominal aorta appears to be similar to WAT. In obese mice, the abdominal PVAT has been described to have a white-like phenotype with a primarily unilocular appearance (Police et al., 2009). Additionally, the mesenteric PVAT has been described to be similar to WAT with large lipid droplets and low expression levels of UCP-1 (Gálvez-Prieto et al., 2008).

Together, these data suggest that the functional phenotype of PVAT is directly linked with its anatomical localization. Thoracic PVAT is phenotypically close to BAT, and shares its unique functional characteristics. Abdominal PVAT, on the other hand, has been described to closely resemble WAT, and has a similar role in obesity-induced inflammatory responses. Furthermore, PVAT does not seem to share the dynamic properties of beige fat: thoracic PVAT displays a BAT-like phenotype without external stimuli, and does not readily lose this phenotype in diet-induced obesity.

\section{Developmental Differences between PVAT, BAT, WAT, and Beige Fat}

While the phenotype of thoracic PVAT may be almost indistinguishable from BAT, the question whether or not it is classical BAT is still not solved. On the other hand, location of PVAT might determine its color/phenotype: some parts of PVAT, e.g., abdominal PVAT, have been reported to resemble WAT (Police et al., 2009; Gálvez-Prieto et al., 2012). During embryogenesis, the mesodermal germ layer gives rise to mesenchymal progenitors that in turn differentiate into all types of adipocyte precursor cells. However, over the last decade, it has become increasingly clear that adipocytes of different adipose tissue depots are derived from precursor cells of distinct lineages. This notion is underlined by the fact that mature adipocytes of different depots appear at different times during embryogenesis (Xue et al., 2007; Wang et al., 2013; Hong et al., 2015). Functional mature brown adipocytes in the interscapular region are necessary for temperature homeostasis immediately at birth, and consequently start developing around 4 days prior to birth (Xue et al., 2007). White adipocytes mostly develop after birth, although significant differences exist between WAT tissues in different depots. This was recently demonstrated by Wang et al., who used an inducible adipocyte labeling system based on the adiponectin promoter to track adipogenesis in vivo (Wang et al., 2013). In this study, visceral adipocytes were found to start developing postnatally, while subcutaneous adipocytes initiated differentiation in the embryo (around E16) (Wang et al., 2013). The latter finding is also corroborated by another study, where flow cytometry and histological analysis revealed a subcutaneous population of lipid-lacking perilipin ${ }^{+} /$adiponectin $^{+}$preadipocytes appearing at E16.5 (Hong et al., 2015). Considering the phenotypical differences between PVAT surrounding different vessels, it is plausible that location-specific differences in PVAT development also exist.

Aside from the temporal regulation of adipocyte differentiation, differences can also be found in the progenitor cells themselves that give rise to mature adipocytes of different depots. De novo adipogenesis of white fat occurs close to blood vessels, and several studies have demonstrated that white adipocytes develop from perivascular platelet-derived growth factor $\alpha$-expressing $\left(\mathrm{Pdgfr}^{+}\right)$progenitor cells (Berry and Rodeheffer, 2013; Hong et al., 2015; Sun et al., 2017). However, adipocyte progenitors cannot be identified solely based on Pdgfra expression, as not all vascular Pdgfra ${ }^{+}$cells are adipogenic (Berry and Rodeheffer, 2013). Other studies have shown that the vascular fraction capable of in vitro adipogenesis is $\mathrm{CD} 31^{-} \mathrm{CD} 34^{+}$, which is an antigen signature that matches adventitial fibroblasts rather than endothelial or mural cells (Guimaraes-Camboa and Evans, 2017; Hepler and Gupta, 2017). White adipocytes that develop in adulthood, e.g., during obesity-induced WAT hyperplasia, likely have a different origin. Here, mature adipocytes derive from specialized mural Pdgfr $\beta^{+}$ precursor cells residing in the blood vessels of adipose tissue, although the exact identity of these cells is unknown (Jiang et al., 2014; Vishvanath et al., 2016).

On the other hand, brown adipocytes appear to stem from myogenic progenitors, and indeed share many characteristics with skeletal muscle cells, such as a similar transcriptome and mitochondrial proteome (Forner et al., 2009). The myogenic transcription factors paired box protein Pax-3 and 7 (Pax3, Pax7), as well as myogenic factor 5 (Myf5), are activated during the early development of brown adipocytes from mesenchymal stem cells (Lepper and Fan, 2010; Sanchez-Gurmaches and Guertin, 2014). From these $\mathrm{Myf}^{+} \mathrm{Pax}^{+}{ }^{+} \mathrm{Pax} 7^{+}$precursors, brown preadipocytes become committed to the brown fat lineage through activation of BMP7 (Park et al., 2013). An earlier study identified PRDM16 as a key determinant of brown adipocyte commitment during development (Seale et al., 2008), but more recent investigations suggest that PRDM16 primarily maintains the BAT phenotype postnatally (Harms et al., 2014). The myogenic lineage described above may not be accurate for all BAT depots, as a recent study, in which detailed lineage analysis were performed, revealed that only the major depots (inter- and subscapular) of BAT are exclusively derived from $\mathrm{Myf}^{+} \mathrm{Pax} 3^{+}$precursors. Furthermore, the myogenic lineage may also not be unique to BAT (SanchezGurmaches and Guertin, 2014): some WAT depots are in fact derived solely from $\mathrm{Myf5}^{+}$cells (Sanchez-Gurmaches and Guertin, 2014). This suggests that certain canonical BAT 
lineage markers may correlate more closely to anatomical localization of the tissue during development, rather than functionality.

Beige cells are often described as inducible brown adipocytes, although there is no consensus concerning the embryonic origin of beige adipocytes (Pfeifer and Hoffmann, 2015). Four possible lineages of beige adipocyte development have been suggested: (1) transdifferentiation of mature white adipocytes (HimmsHagen et al., 2000; Vitali et al., 2012), (2) maturation of brown preadipocytes already existing in WAT (Wang et al., 2014), (3) differentiation and maturation of pre-existing white preadipocytes (Seale et al., 2008), or (4) differentiation from vascular precursors, similarly to what occurs during WAT hyperplasia (Long et al., 2014). In fact, the amounting data from recent studies suggest that all these pathways could contribute to beige adipocyte development, depending on tissue depot and stimuli (Harms and Seale, 2013). While transdifferentiation of mature adipocytes probably only takes place on a low scale (Harms and Seale, 2013), beige adipocytes can arise from brown-like preadipocytes $\left(\mathrm{Myf5}^{+}\right)$or white-like preadipocytes $\left(\mathrm{Myf5}^{-}\right)$depending on the developmental origin of the depot in question (Sanchez-Gurmaches et al., 2012). However, it is not presently clear whether this diverging lineage translates into functional differences. Furthermore, prolonged cold exposure in rodents ( $>2$ weeks) leads to beige adipogenesis from the same mural $\operatorname{Pdgfr} \beta^{+}$precursor population that is responsible for diet-induced WAT hyperplasia (Vishvanath et al., 2016).

Perivascular fat does not share the myogenic lineage of classical brown fat. Rather, PVAT seems to share a developmental origin with vascular smooth muscle (mural) cells. Chang and colleagues deleted the master regulator of adipogenesis PPAR $\gamma$ in smooth muscle by crossing SM $22 \alpha$-Cre mice with PPAR $\gamma^{\text {flox/flox }}$ mice (Chang et al., 2012). This resulted in a complete loss of PVAT, but no change in either WAT or BAT development. The expression of SM22 $\alpha$ in mesenchymal cells proximal to the aorta during early embryogenesis might suggest that PVAT development is initiated during embryonic development, which would distinguish it from other mural-derived adipose tissues ( $\mathrm{Li}$ et al., 1996). However, further investigation is needed to clarify this.

Additionally, thoracic PVAT cells originate from Myf5precursors, further separating them from intrascapular classical brown adipocytes (Sanchez-Gurmaches and Guertin, 2014). Thoracic PVAT also seems to develop differently in males and females: a majority of periaortic adipocytes in females originate from $\mathrm{Pax}^{+}$precursors, while all periaortic adipocytes in males arise from Pax $3^{-}$cells. In contrast, $99-100 \%$ of all interscapular and subscapular brown adipocytes from both genders are derived from $\mathrm{Pax}^{+}$precursors (Sanchez-Gurmaches and Guertin, 2014). In summary, these data suggest that the functional differences between thoracic PVAT and BAT are almost negligible. In contrast, abdominal PVAT has been suggested to closely resemble WAT (Police et al., 2009; Gálvez-Prieto et al., 2012). PVAT might be categorized as a fourth type of fat tissue which seems to be developmentally different from BAT, WAT, and beige fat.

\section{PVAT IN OBESITY-RELATED VASCULAR DISEASE}

\section{Atherosclerosis}

CVD is the leading cause of mortality globally, and is responsible for almost a third of all deaths world-wide (WHO, 2017). The underlying cause of CVD is atherosclerosis, the thickening and hardening of arterial walls because of: (1) endothelial dysfunction, (2) retention and accumulation of low-density lipoprotein (LDL) particles and immune cells in the tunica intima, and (3) proliferation and migration of intimal smooth muscle cells. If unaddressed, this condition can progress to various life-threatening conditions such as thrombosis, myocardial infarction, and stroke (Lusis, 2000).

Inflammation is intimately linked with atherosclerosis. The initial step in atherogenesis is endothelial dysfunction, leading to increased retention of LDL particles in the subendothelial space. The retained particles are then modified in various ways (e.g., oxidation and glycation), which turns them into auto-antigens, inducing a low-grade inflammation (Rader and Daugherty, 2008; Tabas et al., 2015). The inflammatory response activates endothelial cells, leading to increased adhesion and infiltration and monocytes (Madamanchi et al., 2005; Tabas et al., 2015). Intra-intimal differentiation of monocytes into macrophages plays a key role in atherogenesis, and accumulation of the modified LDL particles in these macrophages eventually turns them into the foam cells that are characteristic of atherosclerosis (Tabas et al., 2015). The adaptive immune system is also important for atherogenesis. T-cells and Bcells infiltrate the intima following endothelial cell activation, and have both been demonstrated to regulate the progression of atherosclerosis (Ammirati et al., 2015). Immunodeficiency in mice reduces plaque formation, and reconstituting $\mathrm{CD}_{4}^{+}$ T-cells in scid/scid mice increases it (Dansky et al., 1997; Zhou et al., 2000). Furthermore, selective depletion of $\mathrm{CD}^{+}{ }^{-} \mathrm{T}$ cells using antibodies reduces fatty streak formation in early atherogenesis (Emeson et al., 1996). On the other hand, Bcell depletion by splenectomy increases atherogenesis, and subsequent B-cell transfer from donor mice decreases it, possibly through regulation of T-cell activity (Caligiuri et al., 2002).

\section{PVAT and Inflammation}

While conventional monocyte and T-cell infiltration occurs from the luminal side of the vessel wall, accumulating evidence also suggests that adventitia plays an important role in vascular inflammation. T-cells, B-cells, monocytes, and mature macrophages all reside in the adventitia of diseased vessels (Maiellaro and Taylor, 2007), the former two exceeding their corresponding numbers in the intima of $\mathrm{ApoE}^{-/-}$ mice up to 80 -fold. Furthermore, adventitial vasa vasorum neovascularisation has been shown to precede endothelial dysfunction in hypercholesterolemic pigs (Herrmann et al., 2001). This suggests that immune cell infiltration occurs not only from the luminal side of the vessel (inside-out), but also from the adventitial side (outside-in) (Kawabe and Hasebe, 2014). Considering this, the role of PVAT in arterial inflammation is 
of great interest due to its location to the vessel wall, especially considering the lack of a fascia separating the PVAT from the adventitia. This direct contact enables significant paracrine signaling from PVAT to the vessel wall, and PVAT is indeed known to release numerous paracrine factors that influence the vessel in terms of both inflammation and contractility. Proand anti-inflammatory agents released by PVAT include leptin (Gálvez-Prieto et al., 2012; Li et al., 2014), adiponectin (Lynch et al., 2013; Antonopoulos et al., 2015), resistin (Park et al., 2014), TNF- $\alpha$ (DeVallance et al., 2016), MCP-1 (Manka et al., 2014), TGF- $\beta$ (Chatterjee et al., 2013), angiopoietin-like protein 2 (Angptl2) (Tian et al., 2013), and IL-6 (Du et al., 2015), all of which are known to influence the progression of atherosclerosis in some way:

Adenoviral overexpression of leptin in PVAT promotes neointima formation, and transplantation of PVAT from HFD-fed obese mice, but not leptin-deficient $o b / o b$ mice, to injured vessels increases neointima formation (Schroeter et al., 2013). Additionally, vascular smooth muscle cells (VSMCs) incubated with conditioned medium from the PVAT of HFDfed rats increased leptin-dependent switching to the proliferative, synthetic phenotype characteristic of VSMCs in the neointima ( $\mathrm{Li}$ et al., 2014).

Adiponectin is widely described as anti-inflammatory and protective against atherosclerosis (Xita and Tsatsoulis, 2012; Antonopoulos et al., 2015). Adiponectin-deficient mice have pronounced neointima formation upon wire injury, which can be rescued by local administration of recombinant adiponectin to the adventitial region of the injured vessels (Takaoka et al., 2009). This suggests that adiponectin secreted from PVAT may be protective against neointimal hyperplasia.

PVAT-derived resistin has not been directly shown to influence atherosclerosis, but does increase the expression of osteopontin in VSMCs (Park et al., 2014), which in turn has been implicated in VSMC proliferation and restenosis (Panda et al., 1997; Shimizu et al., 2004).

The effect of PVAT on intimal VSMC infiltration has also been investigated after transplantation of thoracic PVAT to wireinjured carotid arteries, where the presence of PVAT accelerated neointimal formation in an MCP-1 dependent manner (Manka et al., 2014). Interestingly, MCP-1 did not influence the infiltration of macrophages. MCP-1 has also been shown to stimulate VSMC proliferation in vitro (Viedt et al., 2002).

Moreover, inflamed PVAT increases VSMC proliferation in a TGF- $\beta$ dependent manner, suggesting that TGF- $\beta$ released from PVAT can potentiate neointima formation (Moe et al., 2013) The PVAT transplantation approach has also been used to study the effects of PVAT-derived Angptl2 on the progression of neointimal hyperplasia after endovascular injury (Tian et al., 2013). Here, PVAT from mice over-expressing Angptl2 accelerate neointima formation, while PVAT from Angptl $2^{-/-}$mice attenuated it. One should note, however, that the role of VSMC migration and proliferation in atherosclerosis is still debated (Bennett et al., 2016). Recent studies suggest that proliferation of VSMC is mainly protective, stabilizing the late-stage plaque rather than contributing to its formation (Bennett et al., 2016). Experiments in which PVAT has been replaced by other adipose tissue depots also hint to the similarities in paracrine signaling between PVAT and WAT. Two studies have examined the effects of replacing femoral PVAT with VAT and SAT, respectively, on neointimal formation (Takaoka et al., 2009; Tian et al., 2013). Interestingly, both studies arrived at the same result: removal of PVAT exacerbates neointimal hyperplasia, and transplantation of either VAT or SAT attenuates this effect (Takaoka et al., 2009; Tian et al., 2013). These studies corroborate previous reports that femoral PVAT is similar to WAT (Brown et al., 2014).

TNF- $\alpha$ and IL- 6 are also known to accelerate atherogenesis, although evidence of PVAT directly affecting neointima formation via these molecules is lacking (Moe et al., 2013; Hartman and Frishman, 2014). The role of IL-6 seems to be dose-dependent: several studies have confirmed the proinflammatory effects of IL-6 in atherosclerosis models (Hartman and Frishman, 2014), but a complete loss of IL-6 increases plaque formation and serum cholesterol levels in $\mathrm{ApoE}^{-/-}$mice (Schieffer et al., 2004).

Under homeostatic conditions, the anti-inflammatory effects of PVAT predominate, and secretion of pro-inflammatory paracrine agents is relatively low (Police et al., 2009; Fitzgibbons and Czech, 2014). In hypertriglyceridemia and obesity, however, there is significant upregulation of several pro-inflammatory chemokines and macrophage markers in both thoracic and abdominal PVAT (Police et al., 2009). The inflammatory response in thoracic PVAT, however, is quite low in comparison to abdominal PVAT, further supporting the notion that thoracic and abdominal PVAT closely resemble BAT and WAT, respectively (Police et al., 2009; Padilla et al., 2013).

The BAT-like phenotype of thoracic PVAT may also influence the progression of atherosclerosis in an inflammationindependent manner. Cold exposure activates both BAT and thoracic PVAT (Chang et al., 2012), initiating thermogenesis via mitochondrial uncoupling. The high requirement for fuel in this process leads to a dramatic increase in the uptake of circulating triglycerides into BAT, greatly reducing the levels of serum lipoprotein particles in both genetic and diet-induced models of obesity (Bartelt et al., 2011). In fact, activation of BAT has been shown to directly protect from atherogenesis through this mechanism in a recent study (Berbée et al., 2015). Interestingly, this study also addressed lipid uptake into PVAT during stimulation with the $\beta 3$-AR agonist CL316243. Treatment with the agonist significantly increased uptake of lipids from the circulation in manner similar to BAT (Berbée et al., 2015), suggesting that cold exposure could also lead to an amelioration of diet-induced hypertriglyceridemia through PVAT activation, which in turn would slow the progression of atherosclerosis. Interestingly, activation of PVAT through cold exposure has been shown to reduce the expression of pro-inflammatory markers in ferrets, indicating a possible therapeutic role of PVAT in atherosclerosis and other inflammatory vascular diseases (Reynés et al., 2017).

The effects of aging also highlight the phenotypical differences between thoracic and abdominal PVAT. Padilla et al. investigated the expression of several inflammation-related genes in adipose tissues of young and old rats. Although neither thoracic nor abdominal PVAT showed any strong age-related increase in 
any of the analyzed inflammation markers, basal expression of almost all analyzed inflammatory markers was increased in abdominal compared to thoracic PVAT (Padilla et al., 2013). Moreover, abdominal, but not thoracic, PVAT of older rats had higher level of CD11 $\alpha$ and FoxP3, indicating increased immune cell infiltration (Padilla et al., 2013). Bailey-Downs et al. also studied the combined effects of aging and HFD on inflammation in thoracic PVAT in mice (Bailey-Downs et al., 2013). Conditioned medium containing the secretome from PVAT excised from young or old mice fed either HFD or control diet (CD) was applied to aortic segments, and the inflammatory response of the vessels were analyzed. Interestingly, segments incubated with the conditioned medium from HFD-PVAT had higher levels of TNF $\alpha$ and IL-6 expression than segments incubated with conditioned medium from CD-PVAT (BaileyDowns et al., 2013). Analysis of the PVAT itself after HFD or $\mathrm{CD}$ feeding did not reveal any significant increase in macrophage infiltration. This may indicate that while HFD does not necessarily lead to an increased state of inflammation in thoracic PVAT itself, it may contribute to inflammation in the vessel wall through paracrine signaling. In this study, aging strongly exacerbated the effects of HFD, both in terms of vessel inflammation and macrophage infiltration in PVAT (Bailey-Downs et al., 2013).

\section{PVAT and ROS Production}

Recently, a role for PVAT in regulating reactive oxygen species (ROS) production in vessels was described. ROS production by NADPH oxidases is a critical step for the development of endothelial dysfunction in several pathologies, including diabetes, atherosclerosis, and aging (Guzik et al., 2000; Guzik and Harrison, 2006). Analysis of the internal mammary arteries and the adjacent PVAT in a cohort of 386 patients revealed a strong correlation of insulin resistance and type 2 diabetes, with both lower serum adiponectin levels and increased $\mathrm{O}_{2}^{-}$production in the vascular wall. Additionally, artery segments incubated with adiponectin had significantly reduced vascular NADPHdependent $\mathrm{O}_{2}^{-}$production, and scavenging $\mathrm{O}_{2}^{-}$radicals reduced adiponectin expression in PVAT. This study indicates that PVAT can detect ROS production in its adjacent artery, and in turn reduce it by increasing adiponectin expression (Antonopoulos et al., 2015).

ROS production in PVAT has also been implicated in obesity. Aortic PVAT from mice fed a HFD showed an increased TNF$\alpha$ mediated ROS production, with increased contractile tone of the underlying vessel (Ketonen et al., 2010; da Costa et al., 2017). ROS production in thoracic PVAT following HFD is also known to be exacerbated by aging (Bailey-Downs et al., 2013). Whether or not this HFD-induced ROS production is partly responsible for the progression of e.g., atherosclerosis has not been directly studied.

\section{PVAT in Hypertension}

Hypertension is a common complication of obesity and affects almost $60 \%$ of obese individuals (Must et al., 1999). While the development of hypertension in obesity is multifactorial, it can partly be ascribed to the endocrine effects of adipose tissue (Sharma et al., 2001; Re, 2009). In obesity, WAT releases several factors that are known to affect vascular tone and blood pressure (Yiannikouris et al., 2010). These include leptin (Bravo et al., 2006), angiotensin II (Schütten et al., 2017), non-esterified fatty acids (NEFAs) (Sarafidis and Bakris, 2007), adiponectin (Ohashi et al., 2011), and resistin (Zhang et al., 2017). Interestingly, all these factors have been shown to be released from PVAT (see also above) (Lu et al., 2010; Gálvez-Prieto et al., 2012; Campia et al., 2014; Park et al., 2014; Antonopoulos et al., 2015). While this could indicate that PVAT is similar to WAT in terms of its regulation of hypertension, studies examining the role of BAT in hypertension are lacking. Furthermore, in some studies examining the release of the above mentioned factors, it is not immediately clear which type of PVAT was studied, making a thorough comparative analysis impossible (GálvezPrieto et al., 2012; Park et al., 2014). PVAT also releases numerous factors that directly affect vascular tone in a paracrine fashion, including norepinephrine, nitric oxide, hydrogen sulfide, and methyl palmitate (Lee et al., 2011; Chang et al., 2013). However, relating the release of these factors from PVAT to the effects of WAT on systemic vascular tone in obesity is not meaningful.

\section{OUTLOOK}

As the obesity pandemic continues to grow, there is an urgent need for effective pharmacological treatment of both the underlying causes and the associated comorbidities. Understanding the basic biology of the implicated tissues, as well as the pathological alterations and processes, is essential for the development of new therapeutic strategies. So far, the understanding of the role of PVAT in vascular disease is in its infancy, but recent studies indicate that several features of PVAT could have positive effects on the progression of atherosclerosis and endothelial dysfunction in various ways.

While the origin of PVAT seems to be different from BAT, their phenotypes appear almost indistinguishable, both in thermogenic properties and resistance to diet-induced inflammation. The thermogenic capacity of thoracic PVAT, for example, could prove useful in regulating energy expenditure, and should be investigated for a potential role in the treatment of energy balance-related diseases such as obesity and diabetes. Phenotypically and functionally, it is tempting to categorize thoracic PVAT as BAT, and abdominal and femoral PVAT as WAT. However, the developmental origins of PVAT seem to differ from both BAT and WAT, although this remains to be fully elucidated. In summary, the available evidence points to clear differences between PVAT and other adipose tissues. Thus, PVAT might be regarded as neither BAT nor WAT, but rather as a distinct type of adipose tissue.

\section{AUTHOR CONTRIBUTIONS}

All authors listed have made a substantial, direct and intellectual contribution to the work, and approved it for publication.

\section{FUNDING}

JS was supported by the BONFOR research commission of the Medical Faculty, University of Bonn. 


\section{REFERENCES}

Afshin, A., Forouzanfar, M. H., Reitsma, M. B., Sur, P., Estep, K., Lee, A., et al. (2017). Health effects of overweight and obesity in 195 countries over 25 years. N. Engl. J. Med. 377, 13-27. 173-187. doi: 10.1056/NEJMoa1614362

Ammirati, E., Moroni, F., Magnoni, M., and Camici, P. G. (2015). The role of T and $\mathrm{B}$ cells in human atherosclerosis and atherothrombosis. Clin. Exp. Immunol. 179, 173-187. doi: 10.1111/cei.12477

Antonopoulos, A. S., Margaritis, M., Coutinho, P., Shirodaria, C., Psarros, C., Herdman, L., et al. (2015). Adiponectin as a link between type 2 diabetes and vascular NADPH oxidase activity in the human arterial wall: the regulatory role of perivascular adipose tissue. Diabetes 64, 2207-2219. doi: 10.2337/db14-1011

Bailey-Downs, L. C., Tucsek, Z., Toth, P., Sosnowska, D., Gautam, T., Sonntag, W. E., et al. (2013). Aging exacerbates obesity-induced oxidative stress and inflammation in perivascular adipose tissue in mice: a paracrine mechanism contributing to vascular redox dysregulation and inflammation. J. Gerontol. A Biol. Sci. Med. Sci. 68, 780-792. doi: 10.1093/gerona/gls238

Barak, Y., Nelson, M. C., Ong, E. S., Jones, Y. Z., Ruiz-Lozano, P., Chien, K. R., et al. (1999). PPAR gamma is required for placental, cardiac, and adipose tissue development. Mol. Cell 4, 585-595. doi: 10.1016/S1097-2765(00)80209-9

Bartelt, A., Bruns, O. T., Reimer, R., Hohenberg, H., Ittrich, H., Peldschus, K., et al. (2011). Brown adipose tissue activity controls triglyceride clearance. Nat. Med. 17, 200-205. doi: 10.1038/nm.2297

Bennett, M. R., Sinha, S., and Owens, G. K. (2016). Vascular smooth muscle cells in Atherosclerosis. Circ. Res. 118, 692-702. doi: 10.1161/CIRCRESAHA.115.306361

Berbée, J. F., Boon, M. R., Khedoe, P. P., Bartelt, A., Schlein, C., Worthmann, A., et al. (2015). Brown fat activation reduces hypercholesterolaemia and protects from atherosclerosis development. Nat. Commun. 6:6356. doi: $10.1038 /$ ncomms 7356

Berry, R., and Rodeheffer, M. S. (2013). Characterization of the adipocyte cellular lineage in vivo. Nat. Cell Biol. 15, 302-308. doi: 10.1038/ncb2696

Bravo, P. E., Morse, S., Borne, D. M., Aguilar, E. A., and Reisin, E. (2006). Leptin and hypertension in obesity. Vasc. Health Risk Manag. 2, 163-169. doi: 10.2147/vhrm.2006.2.2.163

Britton, K. A., and Fox, C. S. (2011). Perivascular adipose tissue and vascular disease. Clin. Lipidol. 6, 79-91. doi: 10.2217/clp.10.89

Brown, N. K., Zhou, Z., Zhang, J., Zeng, R., Wu, J., Eitzman, D. T., et al. (2014). Perivascular adipose tissue in vascular function and disease: a review of current research and animal models. Arterioscler. Thromb. Vasc. Biol. 34, 1621-1630. doi: 10.1161/ATVBAHA.114.303029

Caligiuri, G., Nicoletti, A., Poirier, B., and Hansson, G. K. (2002). Protective immunity against atherosclerosis carried by B cells of hypercholesterolemic mice. J. Clin. Invest. 109, 745-753. doi: 10.1172/JCI7272

Campia, U., Tesauro, M., Di Daniele, N., and Cardillo, C. (2014). The vascular endothelin system in obesity and type 2 diabetes: pathophysiology and therapeutic implications. Life Sci. 118, 149-155. doi: 10.1016/j.lfs.2014.02.028

Cannon, B., and Nedergaard, J. (2004). Brown adipose tissue: function and physiological significance. Physiol. Rev. 84, 277-359. doi: 10.1152/physrev.00015.2003

Chang, L., Milton, H., Eitzman, D. T., and Chen, Y. E. (2013). Paradoxical roles of perivascular adipose tissue in atherosclerosis and hypertension. Circ. J. 77, 11-18. doi: 10.1253/circj.CJ-12-1393

Chang, L., Villacorta, L., Li, R., Hamblin, M., Xu, W., Dou, C., et al. (2012). Loss of perivascular adipose tissue on peroxisome proliferator-activated receptor-gamma deletion in smooth muscle cells impairs intravascular thermoregulation and enhances atherosclerosis. Circulation 126, 1067-1078. doi: 10.1161/CIRCULATIONAHA.112.104489

Chatterjee, T. K., Aronow, B. J., Tong, W. S., Manka, D., Tang, Y., Bogdanov, V. Y., et al. (2013). Human coronary artery perivascular adipocytes overexpress genes responsible for regulating vascular morphology, inflammation, and hemostasis. Physiol. Genomics. 45, 697-709. doi: 10.1152/physiolgenomics.00042.2013

Chen, Y., Pan, R., and Pfeifer, A. (2016). Fat tissues, the brite and the dark sides. Pflugers Arch. 468, 1803-1807. doi: 10.1007/s00424-016-1884-8

Chen, Y., Pan, R., and Pfeifer, A. (2017). Regulation of brown and beige fat by microRNAs. Pharmacol. Ther. 170, 1-7. doi: 10.1016/j.pharmthera.2016.10.004

Cohen, P., Levy, J. D., Zhang, Y., Frontini, A., Kolodin, D. P., Svensson, K. J., et al. (2014). Ablation of PRDM16 and beige adipose causes metabolic dysfunction and a subcutaneous to visceral fat switch. Cell 156, 304-316. doi: 10.1016/j.cell.2013.12.021

Cypess, A. M., Lehman, S., Williams, G., Tal, I., Rodman, D., Goldfine, A. B., et al. (2009). Identification and importance of brown adipose tissue in adult humans. N. Engl. J. Med. 360, 1509-1517. doi: 10.1056/NEJMoa0810780

Czech, M. P., Richardson, D. K., and Smith, C. J. (1977). Biochemical basis of fat cell insulin resistance in obese rodents and man. Metab. Clin. Exp. 26, 1057-1078. doi: 10.1016/0026-0495(77)90024-5

da Costa, R. M., Fais, R. S., Dechandt, R. P. C., Louzada-Junior, P., Alberici, L. C., Lobato, N. S., et al. (2017). Increased mitochondrial ROS generation mediates the loss of the anti-contractile effects of perivascular adipose tissue in high-fat diet obese mice. Br. J. Pharmacol. 174, 3527-3541. doi: 10.1111/bph.13687

Dansky, H. M., Charlton, S. A., Harper, M. M., and Smith, J. D. (1997). T and B lymphocytes play a minor role in atherosclerotic plaque formation in the apolipoprotein E-deficient mouse. Proc. Natl. Acad. Sci. U.S.A. 94, 4642-4646. doi: 10.1073/pnas.94.9.4642

DeVallance, E., Branyan, K., Lemaster, K., Brooks, S., Asano, S., Skinner, R., et al. (2016). Perivascular adipose tissue derived TNF $\alpha$ neutralization recovers aortic function in metabolic syndrome. FASEB J. 30:1282.7. doi: 10.1096/fasebj.30.1_supplement.1282.7

Du, B., Ouyang, A., Eng, J. S., and Fleenor, B. S. (2015). Aortic perivascular adiposederived interleukin-6 contributes to arterial stiffness in low-density lipoprotein receptor deficient mice. Am. J. Physiol. Heart Circ. Physiol. 308, H1382-H1390. doi: 10.1152/ajpheart.00712.2014

Duncan, R. E., Ahmadian, M., Jaworski, K., Sarkadi-Nagy, E., and Sul, H. S. (2007). Regulation of lipolysis in adipocytes. Annu. Rev. Nutr. 27, 79-101. doi: 10.1146/annurev.nutr.27.061406.093734

Emeson, E. E., Shen, M. L., Bell, C. G., and Qureshi, A. (1996). Inhibition of atherosclerosis in CD4 T-cell-ablated and nude (nu/nu) C57BL/6 hyperlipidemic mice. Am. J. Pathol. 149, 675-685.

Fantuzzi, G., and Mazzone, T. (2007). Adipose tissue and atherosclerosis: exploring the connection. Arterioscler. Thromb. Vasc. Biol. 27, 996-1003. doi: 10.1161/ATVBAHA.106.131755

Fitzgibbons, T. P., and Czech, M. P. (2014). Epicardial and perivascular adipose tissues and their influence on cardiovascular disease: basic mechanisms and clinical associations. J. Am. Heart Assoc. 3:e000582. doi: 10.1161/JAHA.113.000582

Fitzgibbons, T. P., Kogan, S., Aouadi, M., Hendricks, G. M., Straubhaar, J., and Czech, M. P. (2011). Similarity of mouse perivascular and brown adipose tissues and their resistance to diet-induced inflammation. Am. J. Physiol. Heart Circ. Physiol. 301, H1425-H1437. doi: 10.1152/ajpheart.00376.2011

Forner, F., Kumar, C., Luber, C. A., Fromme, T., Klingenspor, M., and Mann, M. (2009). Proteome differences between brown and white fat mitochondria reveal specialized metabolic functions. Cell Metab. 10, 324-335. doi: 10.1016/j.cmet.2009.08.014

Gálvez-Prieto, B., Bolbrinker, J., Stucchi, P., de Las Heras, A. I., Merino, B., Arribas, S. et al. (2008). Comparative expression analysis of the renin-angiotensin system components between white and brown perivascular adipose tissue. $J$. Endocrinol. 197, 55-64. doi: 10.1677/JOE-07-0284

Gálvez-Prieto, B., Somoza, B., Gil-Ortega, M., García-Prieto, C. F., de Las Heras, A. I., González, M. C., et al. (2012). Anticontractile effect of perivascular adipose tissue and leptin are reduced in hypertension. Front. Pharmacol. 3:103. doi: 10.3389/fphar.2012.00103

Gao, Y. J., Lu, C., Su, L. Y., Sharma, A. M., and Lee, R. M. (2007). Modulation of vascular function by perivascular adipose tissue: the role of endothelium and hydrogen peroxide. Br. J. Pharmacol. 151, 323-331. doi: 10.1038/sj.bjp.0707228

Gnad, T., Scheibler, S., von Kügelgen, I., Scheele, C., Kilić, A., Glöde, A., et al. (2014). Adenosine activates brown adipose tissue and recruits beige adipocytes via A2A receptors. Nature. 516, 395-399. doi: 10.1038/nature13816

Gollasch, M., and Dubrovska, G. (2004). Paracrine role for periadventitial adipose tissue in the regulation of arterial tone. Trends Pharmacol. Sci. 25, 647-653. doi: 10.1016/j.tips.2004.10.005

Guilherme, A., Virbasius, J. V., Puri, V., and Czech, M. P. (2008). Adipocyte dysfunctions linking obesity to insulin resistance and type 2 diabetes. Nat. Rev. Mol. Cell Biol. 9, 367-377. doi: 10.1038/nrm2391

Guimaraes-Camboa, N., and Evans, S. M. (2017). Are perivascular adipocyte progenitors mural cells or adventitial fibroblasts? Cell Stem Cell 20, 587-589. doi: 10.1016/j.stem.2017.04.010 
Guzik, T. J., and Harrison, D. G. (2006). Vascular NADPH oxidases as drug targets for novel antioxidant strategies. Drug Discov. Today 11, 524-533. doi: 10.1016/j.drudis.2006.04.003

Guzik, T. J., West, N. E., Black, E., McDonald, D., Ratnatunga, C., Pillai, R., et al. (2000). Vascular superoxide production by NAD(P)H oxidase: association with endothelial dysfunction and clinical risk factors. Circ. Res. 86, E85-E90. doi: 10.1161/01.RES.86.9.e85

Harms, M. J., Ishibashi, J., Wang, W., Lim, H. W., Goyama, S., Sato, T., et al. (2014). Prdm16 is required for the maintenance of brown adipocyte identity and function in adult mice. Cell Metab. 19, 593-604. doi: 10.1016/j.cmet.2014.03.007

Harms, M., and Seale, P. (2013). Brown and beige fat: development, function and therapeutic potential. Nat. Med. 19, 1252-1263. doi: 10.1038/nm.3361

Hartman, J., and Frishman, W. H. (2014). Inflammation and atherosclerosis: a review of the role of interleukin- 6 in the development of atherosclerosis and the potential for targeted drug therapy. Cardiol. Rev. 22, 147-151. doi: 10.1097/CRD.0000000000000021

Heaton, J. M. (1972). Distribution of Brown Adipose-Tissue in Human. J. Anat. 112(Pt 1), 35-39.

Hepler, C., and Gupta, R. K. (2017). The expanding problem of adipose depot remodeling and postnatal adipocyte progenitor recruitment. Mol. Cell. Endocrinol. 445, 95-108. doi: 10.1016/j.mce.2016.10.011

Herrmann, J., Lerman, L. O., Rodriguez-Porcel, M., D. R., Holmes Jr, Richardson, D. M., Ritman, E. L., et al. (2001). Coronary vasa vasorum neovascularization precedes epicardial endothelial dysfunction in experimental hypercholesterolemia. Cardiovasc. Res. 51, 762-766. doi: 10.1016/S0008-6363(01)00347-9

Himms-Hagen, J., Melnyk, A., Zingaretti, M. C., Ceresi, E., Barbatelli, G., and Cinti, S. (2000). Multilocular fat cells in WAT of CL-316243-treated rats derive directly from white adipocytes. Am. J. Physiol. Cell Physiol. 279, C670C681.doi: 10.1152/ajpcell.2000.279.3.C670

Hondares, E., Rosell, M., Diaz-Delfin, J., Olmos, Y., Monsalve, M., Iglesias, R., et al. (2011). Peroxisome proliferator-activated receptor alpha (PPAR alpha) induces PPAR gamma coactivator 1 alpha (PGC-1 alpha) gene expression and contributes to thermogenic activation of brown fat INVOLVEMENT OF PRDM16. J. Biol. Chem. 286, 43112-43122. doi: 10.1074/jbc.M111. 252775

Hong, K. Y., Bae, H., Park, I., Park, D. Y., Kim, K. H., Kubota, Y., et al. (2015). Perilipin ${ }^{+}$embryonic preadipocytes actively proliferate along growing vasculatures for adipose expansion. Development 142, 2623-2632. doi: $10.1242 /$ dev.125336

Hotamisligil, G. S. (2006). Inflammation and metabolic disorders. Nature. 444, 860-867. doi: 10.1038/nature05485

Hudak, C. S., and Sul, H. S. (2013). Pref-1, a gatekeeper of adipogenesis. Front. Endocrinol. 4:79. doi: 10.3389/fendo.2013.00079

Jiang, Y., Berry, D. C., Tang, W., and Graff, J. M. (2014). Independent stem cell lineages regulate adipose organogenesis and adipose homeostasis. Cell Rep. 9, 1007-1022. doi: 10.1016/j.celrep.2014.09.049

Kawabe, J., and Hasebe, N. (2014). Role of the vasa vasorum and vascular resident stem cells in atherosclerosis. Biomed Res. Int. 2014:701571. doi: 10.1155/2014/701571

Ketonen, J., Shi, J., Martonen, E., and Mervaala, E. (2010). Periadventitial adipose tissue promotes endothelial dysfunction via oxidative stress in diet-induced obese C57Bl/6 mice. Circ J. 74, 1479-1487. doi: 10.1253/circj.CJ-09-0661

Lee, Y. C., Chang, H. H., Chiang, C. L., Liu, C. H., Yeh, J. I., Chen, M. F., et al. (2011). Role of perivascular adipose tissue-derived methyl palmitate in vascular tone regulation and pathogenesis of hypertension. Circulation 124, 1160-1171. doi: 10.1161/CIRCULATIONAHA.111.027375

Lepper, C., and Fan, C. M. (2010). Inducible lineage tracing of Pax7-descendant cells reveals embryonic origin of adult satellite cells. Genesis 48, 424-436. doi: 10.1002/dvg.20630

Li, H., Wang, Y. P., Zhang, L. N., and Tian, G. (2014). Perivascular adipose tissuederived leptin promotes vascular smooth muscle cell phenotypic switching via p38 mitogen-activated protein kinase in metabolic syndrome rats. Exp. Biol. Med. 239, 954-965. doi: 10.1177/1535370214527903

Li, L., Miano, J. M., Mercer, B., and Olson, E. N. (1996). Expression of the SM22alpha promoter in transgenic mice provides evidence for distinct transcriptional regulatory programs in vascular and visceral smooth muscle cells. J. Cell Biol. 132, 849-859. doi: 10.1083/jcb.132.5.849
Lo, K. A., and Sun, L. (2013). Turning WAT into BAT: a review on regulators controlling the browning of white adipocytes. Biosci. Rep. 33, 711-719. doi: 10.1042/BSR20130046

Long, J. Z., Svensson, K. J., Tsai, L., Zeng, X., Roh, H. C., Kong, X., et al. (2014). A smooth muscle-like origin for beige adipocytes. Cell Metab. 19, 810-820. doi: 10.1016/j.cmet.2014.03.025

Lowell, B. B., and Flier, J. S. (1997). Brown adipose tissue, beta 3adrenergic receptors, and obesity. Annu. Rev. Med. 48, 307-316. doi: 10.1146/annurev.med.48.1.307

Lu, C., Su, L. Y., Lee, R. M., and Gao, Y. J. (2010). Mechanisms for perivascular adipose tissue-mediated potentiation of vascular contraction to perivascular neuronal stimulation: the role of adipocyte-derived angiotensin II. Eur. J. Pharmacol. 634, 107-112. doi: 10.1016/j.ejphar.2010.02.006

Lusis, A. J. (2000). Atherosclerosis. Nature 407, 233-241. doi: 10.1038/35025203

Lynch, F. M., Withers, S. B., Yao, Z., Werner, M. E., Edwards, G., Weston, A. H., et al. (2013). Perivascular adipose tissue-derived adiponectin activates BK(Ca) channels to induce anticontractile responses. Am. J. Physiol. Heart Circ. Physiol. 304, H786-H795. doi: 10.1152/ajpheart.00697.2012.

Madamanchi, N. R., Vendrov, A., and Runge, M. S. (2005). Oxidative stress and vascular disease. Arterioscler. Thromb. Vasc. Biol. 25, 29-38. doi: 10.1161/01.ATV.0000150649.39934.13

Maiellaro, K., and Taylor, W. R. (2007). The role of the adventitia in vascular inflammation. Cardiovasc. Res. 75, 640-648. doi: 10.1016/j.cardiores.2007.06.023

Manka, D., Chatterjee, T. K., Stoll, L. L., Basford, J. E., Konaniah, E. S., Srinivasan, R., et al. (2014). Transplanted perivascular adipose tissue accelerates injury-induced neointimal hyperplasia: role of monocyte chemoattractant protein-1. Arterioscler. Thromb. Vasc. Biol. 34, 1723-1730. doi: 10.1161/ATVBAHA.114.303983

Moe, K. T., Naylynn, T. M., Yin, N. O., Khairunnisa, K., Allen, J. C., Wong, M. C., et al. (2013). Tumor necrosis factor-alpha induces aortic intima-media thickening via perivascular adipose tissue inflammation. J. Vasc. Res. 50, 228-237. doi: 10.1159/000350542

Must, A., Spadano, J., Coakley, E. H., Field, A. E., Colditz, G., and Dietz, W. H. (1999). The disease burden associated with overweight and obesity. JAMA 282, 1523-1529. doi: 10.1001/jama.282.16.1523

Nedergaard, J., Bengtsson, T., and Cannon, B. (2007). Unexpected evidence for active brown adipose tissue in adult humans. Am. J. Physiol. Endocrinol. Metab. 293, E444-E452. doi: 10.1152/ajpendo.00691.2006

Ohashi, K., Ouchi, N., and Matsuzawa, Y. (2011). Adiponectin and hypertension. Am. J. Hypertens. 24, 263-269. doi: 10.1038/ajh.2010.216

Omar, A., Chatterjee, T. K., Tang, Y. L., Hui, D. Y., and Weintraub, N. L. (2014). Proinflammatory phenotype of perivascular adipocytes. Arterioscler. Thromb. Vasc. Biol. 34, 1631-1636. doi: 10.1161/ATVBAHA.114.303030

Padilla, J., Jenkins, N. T., Vieira-Potter, V. J., and Laughlin, M. H. (2013). Divergent phenotype of rat thoracic and abdominal perivascular adipose tissues. Am. J. Physiol. Regul. Integr. Comp. Physiol. 304, R543-R552. doi: 10.1152/ajpregu.00567.2012

Panda, D., Kundu, G. C., Lee, B. I., Peri, A., Fohl, D., Chackalaparampil, I., et al. (1997). Potential roles of osteopontin and alphaVbeta3 integrin in the development of coronary artery restenosis after angioplasty. Proc. Natl. Acad. Sci. U.S.A. 94, 9308-9313. doi: 10.1073/pnas.94.17.9308

Park, J. H., Kang, H. J., Kang, S. I., Lee, J. E., Hur, J., Ge, K., et al. (2013). A multifunctional protein, EWS, is essential for early brown fat lineage determination. Dev. Cell 26, 393-404. doi: 10.1016/j.devcel.2013. 07.002

Park, S. Y., Kim, K. H., Seo, K. W., Bae, J. U., Kim, Y. H., Lee, S. J., et al. (2014). Resistin derived from diabetic perivascular adipose tissue up-regulates vascular expression of osteopontin via the AP-1 signalling pathway. J. Pathol. 232, 87-97. doi: $10.1002 /$ path.4286

Pfeifer, A., and Hoffmann, L. S. (2015). Brown, beige, and white: the new color code of fat and its pharmacological implications. Annu. Rev. Pharmacol. Toxicol. 55, 207-227. doi: 10.1146/annurev-pharmtox-010814-124346

Police, S. B., Thatcher, S. E., Charnigo, R., Daugherty, A., and Cassis, L. A. (2009). Obesity promotes inflammation in periaortic adipose tissue and angiotensin II-induced abdominal aortic aneurysm formation. Arterioscler. Thromb. Vasc. Biol. 29, 1458-1464. doi: 10.1161/ATVBAHA.109.192658

Rader, D. J., and Daugherty, A. (2008). Translating molecular discoveries into new therapies for atherosclerosis. Nature 451, 904-913. doi: 10.1038/nature06796 
Re, R. N. (2009). Obesity-related hypertension. Ochsner. J. 9, $133-136$.

Reynés, B., van Schothorst, E. M., García-Ruiz, E., Keijer, J., Palou, A., and Oliver, P. (2017). Cold exposure down-regulates immune response pathways in ferret aortic perivascular adipose tissue. Thromb. Haemost. 117, 981-991. doi: 10.1160/TH16-12-0931

Rosen, E. D., and MacDougald, O. A. (2006). Adipocyte differentiation from the inside out. Nat. Rev. Mol. Cell Biol. 7, 885-896. doi: 10.1038/nrm2066

Rosen, E. D., Sarraf, P., Troy, A. E., Bradwin, G., Moore, K., Milstone, D. S., et al. (1999). PPAR gamma is required for the differentiation of adipose tissue in vivo and in vitro. Mol. Cell. 4, 611-617. doi: 10.1016/S1097-2765(00)80211-7

Rosenwald, M., Perdikari, A., Rülicke, T., and Wolfrum, C. (2013). Bi-directional interconversion of brite and white adipocytes. Nat. Cell Biol. 15, 659-667. doi: $10.1038 /$ ncb2740

Sanchez-Gurmaches, J., and Guertin, D. A. (2014). Adipocytes arise from multiple lineages that are heterogeneously and dynamically distributed. Nat. Commun. 5:4099. doi: $10.1038 /$ ncomms5099

Sanchez-Gurmaches, J., Hung, C. M., Sparks, C. A., Tang, Y., Li, H., and Guertin, D. A. (2012). PTEN loss in the Myf5 lineage redistributes body fat and reveals subsets of white adipocytes that arise from Myf5 precursors. Cell Metab. 16, 348-362. doi: 10.1016/j.cmet.2012.08.003

Sarafidis, P. A., and Bakris, G. L. (2007). Non-esterified fatty acids and blood pressure elevation: a mechanism for hypertension in subjects with obesity/insulin resistance? J. Hum. Hypertens. 21, 12-19. doi: 10.1038/sj.jhh.1002103

Schieffer, B., Selle, T., Hilfiker, A., Hilfiker-Kleiner, D., Grote, K., Tietge, U. J., et al. (2004). Impact of interleukin-6 on plaque development and morphology in experimental atherosclerosis. Circulation 110, 3493-3500. doi: 10.1161/01.CIR.0000148135.08582.97

Schroeter, M. R., Eschholz, N., Herzberg, S., Jerchel, I., Leifheit-Nestler, M., Czepluch, F. S., et al. (2013). Leptin-dependent and leptinindependent paracrine effects of perivascular adipose tissue on neointima formation. Arterioscler. Thromb. Vasc. Biol. 33, 980-987. doi: 10.1161/ATVBAHA.113.301393

Schütten, M. T., Houben, A. J., de Leeuw, P. W., and Stehouwer, C. D. (2017). The Link between adipose tissue renin-angiotensin-aldosterone system signaling and obesity-associated hypertension. Physiology 32, 197-209. doi: 10.1152/physiol.00037.2016

Seale, P., Bjork, B., Yang, W. L., Kajimura, S., Chin, S., Kuang, S. H., et al. (2008). PRDM16 controls a brown fat/skeletal muscle switch. Nature 454, 961-967. doi: $10.1038 /$ nature 07182

Seale, P., Conroe, H. M., Estall, J., Kajimura, S., Frontini, A., Ishibashi, J., et al. (2011). Prdm16 determines the thermogenic program of subcutaneous white adipose tissue in mice. J. Clin. Invest. 121, 96-105. doi: 10.1172/JCI44271

Sharma, A. M., Engeli, S., and Pischon, T. (2001). New developments in mechanisms of obesity-induced hypertension: role of adipose tissue. Curr. Hypertens. Rep. 3, 152-156. doi: 10.1007/s11906-001-0030-x

Shimizu, H., Takahashi, M., Takeda, S., Inoue, S., Fujishiro, J., Hakamata, Y., et al. (2004). Mycophenolate mofetil prevents transplant arteriosclerosis by direct inhibition of vascular smooth muscle cell proliferation. Transplantation 77 , 1661-1667. doi: 10.1097/01.TP.0000127592.13707.B6

Shimizu, I., Aprahamian, T., Kikuchi, R., Shimizu, A., Papanicolaou, K. N., MacLauchlan, S., et al. (2014). Vascular rarefaction mediates whitening of brown fat in obesity. J. Clin. Invest. 124, 2099-2112. doi: 10.1172/JCI71643

Soltis, E. E., and Cassis, L. A. (1991). Influence of perivascular adiposetissue on rat aortic smooth-muscle responsiveness. Clin. Exp. Hypertens. Part A-Theory Prac. 13, 277-296. doi: 10.3109/106419691090 42063

Sun, C., Berry, W. L., and Olson, L. E. (2017). PDGFRalpha controls the balance of stromal and adipogenic cells during adipose tissue organogenesis. Development 144, 83-94. doi: $10.1242 / \mathrm{dev} .135962$

Tabas, I., García-Cardeña, G., and Owens, G. K. (2015). Recent insights into the cellular biology of atherosclerosis. J. Cell Biol. 209, 13-22. doi: $10.1083 /$ jcb.201412052
Takaoka, M., Nagata, D., Kihara, S., Shimomura, I., Kimura, Y., Tabata, Y., et al. (2009). Periadventitial adipose tissue plays a critical role in vascular remodeling. Circ. Res. 105, 906-911. doi: 10.1161/CIRCRESAHA.109.199653

Tian, Z., Miyata, K., Tazume, H., Sakaguchi, H., Kadomatsu, T., Horio, E., et al. (2013). Perivascular adipose tissue-secreted angiopoietin-like protein 2 (Angpt12) accelerates neointimal hyperplasia after endovascular injury. J. Mol. Cell. Cardiol. 57, 1-12. doi: 10.1016/j.yjmcc.2013.01.004

Tseng, Y. H., Kokkotou, E., Schulz, T. J., Huang, T. L., Winnay, J. N., Taniguchi, C. M., et al. (2008). New role of bone morphogenetic protein 7 in brown adipogenesis and energy expenditure. Nature 454, 1000-1004. doi: 10.1038 /nature 07221

van Marken Lichtenbelt, W. D., Vanhommerig, J. W., Smulders, N. M., Drossaerts, J. M., Kemerink, G. J., Bouvy, N. D. et al. (2009). Cold-activated brown adipose tissue in healthy men. N. Engl. J. Med. 360, 1500-1508. doi: 10.1056/NEJMoa0808718

Viedt, C., Vogel, J., Athanasiou, T., Shen, W., Orth, S. R., Kübler, W., et al. (2002). Monocyte chemoattractant protein-1 induces proliferation and interleukin-6 production in human smooth muscle cells by differential activation of nuclear factor-kappaB and activator protein-1. Arterioscler. Thromb. Vasc. Biol. 22, 914-920. doi: 10.1161/01.ATV.0000019009.73586.7F

Vishvanath, L., MacPherson, K. A., Hepler, C., Wang, Q. A., Shao, M., Spurgin, S. B., et al. (2016). Pdgfrbeta+ mural preadipocytes contribute to adipocyte hyperplasia induced by high-fat-diet feeding and prolonged cold exposure in adult mice. Cell Metab. 23, 350-359. doi: 10.1016/j.cmet.2015. 10.018

Vitali, A., Murano, I., Zingaretti, M. C., Frontini, A., Ricquier, D., and Cinti, S. (2012). The adipose organ of obesity-prone C57BL/6J mice is composed of mixed white and brown adipocytes. J. Lipid Res. 53, 619-629. doi: 10.1194/jlr.M018846

Wang, Q. A., Tao, C., Gupta, R. K., and Scherer, P. E. (2013). Tracking adipogenesis during white adipose tissue development, expansion and regeneration. Nat. Med. 19, 1338-1344. doi: 10.1038/nm.3324

Wang, W., Kissig, M., Rajakumari, S., Huang, L., Lim, H. W., Won, K. J., et al. (2014). Ebf2 is a selective marker of brown and beige adipogenic precursor cells. Proc. Natl. Acad. Sci. U.S.A. 111, 14466-14471. doi: 10.1073/pnas.1412685111

WHO (2017). Cardiovascular Diseases (CVDs) Fact Sheet. Available online at: http://www.who.int/mediacentre/factsheets/fs317/en/ (Acessed Nov 18, 2017).

Xita, N., and Tsatsoulis, A. (2012). Adiponectin in diabetes mellitus. Curr. Med. Chem. 19, 5451-5458. doi: 10.2174/092986712803833182

Xue, B., Rim, J. S., Hogan, J. C., Coulter, A. A., Koza, R. A., and Kozak, L. P. (2007). Genetic variability affects the development of brown adipocytes in white fat but not in interscapular brown fat. J. Lipid Res. 48, 41-51. doi: 10.1194/jlr.M600287-JLR200

Yiannikouris, F., Gupte, M., Putnam, K., and Cassis, L. (2010). Adipokines and blood pressure control. Curr. Opin. Nephrol. Hypertens. 19, 195-200. doi: 10.1097/MNH.0b013e3283366cd0

Zhang, Y., Li, Y., Yu, L., and Zhou, L. (2017). Association between serum resistin concentration and hypertension: a systematic review and meta-analysis. Oncotarget 8, 41529-41537. doi: 10.18632/oncotarget.17561

Zhou, X., Nicoletti, A., Elhage, R., and Hansson, G. K. (2000). Transfer of CD4 ${ }^{+}$T cells aggravates atherosclerosis in immunodeficient apolipoprotein $\mathrm{E}$ knockout mice. Circulation 102, 2919-2922. doi: 10.1161/01.CIR.102.24.2919

Conflict of Interest Statement: The authors declare that the research was conducted in the absence of any commercial or financial relationships that could be construed as a potential conflict of interest.

Copyright (๑) 2018 Hildebrand, Stümer and Pfeifer. This is an open-access article distributed under the terms of the Creative Commons Attribution License (CC $B Y)$. The use, distribution or reproduction in other forums is permitted, provided the original author(s) and the copyright owner are credited and that the original publication in this journal is cited, in accordance with accepted academic practice. No use, distribution or reproduction is permitted which does not comply with these terms. 